\title{
Evaluating Utility Costs Savings for EV Charging Infrastructure
}

Emma Elgqvist \& Josiah Pohl, NREL

November 2019 


\section{Disclaimer}

- This work was authored by the National Renewable Energy Laboratory, operated by Alliance for Sustainable Energy, LLC, for the U.S. Department of Energy (DOE) under Contract No. DE-AC36-08GO28308. Funding provided by the U.S. Department of Energy Office of Energy Efficiency and Renewable Energy Solar Energy Technologies Office. The views expressed in the article do not necessarily represent the views of the DOE or the U.S. Government. The U.S. Government retains and the publisher, by accepting the article for publication, acknowledges that the U.S. Government retains a nonexclusive, paid-up, irrevocable, worldwide license to publish or reproduce the published form of this work, or allow others to do so, for U.S. Government purposes.

- This analysis was conducted as a part of the Solar Energy Innovation Network (SEIN) and relies on site information provided to NREL by the Minnesota SEIN Team that has not been independently validated by NREL. See https://www.nrel.gov/solar/solar-energy-innovationnetwork.html for more information about SEIN and the Minnesota-based team (the full team title is "Technological and Market Deployment Synergies between EVs and Solar DG Using EV Charging to Add Value to Distributed Solar.")

- The analysis results are not intended to be the sole basis of investment, policy, or regulatory decisions.

- This analysis was conducted using the NREL REopt Model (http://www.reopt.nrel.gov). REopt is a techno-economic decision support model that identifies the cost-optimal set of energy technologies and dispatch strategy to meet site energy requirements at minimum lifecycle cost, based on physical characteristics of the site and assumptions about energy technology costs and electricity and fuel prices.

- The data, results, conclusions, and interpretations presented in this document have not been reviewed by technical experts outside NREL or the Minnesota SEIN Team. 


\section{Analysis Overview}

- As part of the Solar Energy Innovation Network, NREL used a tool called REopt to evaluate the impact on utility costs of light duty electric vehicle (EV) charging stations in Minnesota.

- Specifically, this analysis explores:

- How can photovoltaics (PV) and stationary storage be co-deployed with EV charging infrastructure to lower the cost of purchasing grid electricity?

- What are the potential savings of co-locating EV charging infrastructure with (behind the meter of) a commercial building?

- What savings can be gained from optimizing the times at which the EVs are charged to decrease lifecycle costs?

- The lifecycle costs evaluated in this analysis do not include the capital cost of purchasing the

EV chargers. 


\section{REopt Model Overview}

Formulated as a mixedinteger linear program, the REopt model optimizes the integration and operation of behind-the-meter energy assets.

REopt solves a deterministic optimization problem to determine the optimal selection, sizing, and dispatch strategy of technologies chosen from a candidate pool such that loads are met at every time step at the minimum lifecycle cost.

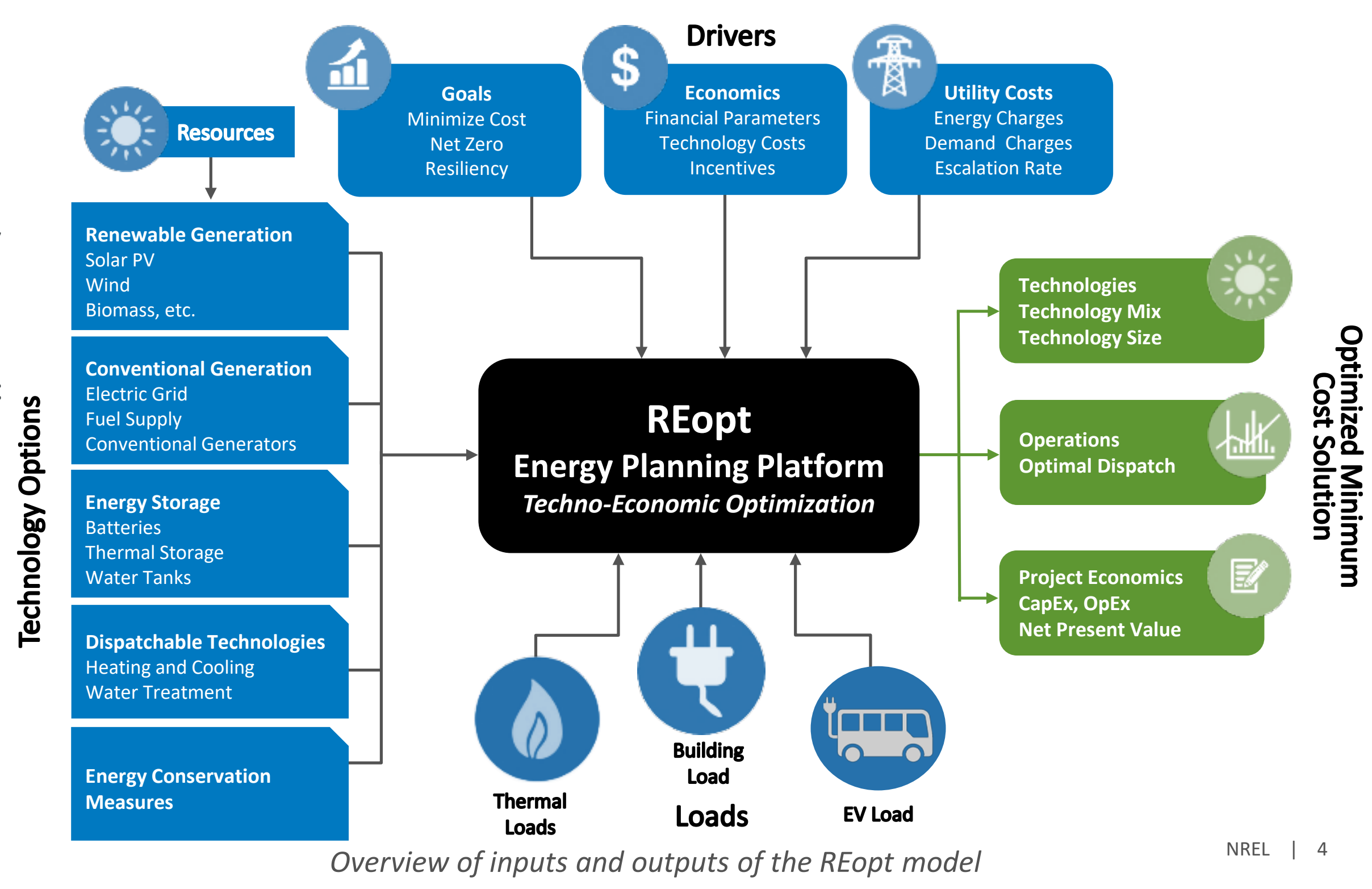




\section{Input Data and Analysis}

Assumptions 


\section{Input Data Overview}

\begin{tabular}{|c|c|c|c|}
\hline Data & Source & Options & Selection \\
\hline $\begin{array}{l}\text { Solar } \\
\text { Resource }\end{array}$ & $\underline{\text { PVWatts }}$ & Location, configuration & Minneapolis, MN \\
\hline $\begin{array}{l}\text { Building } \\
\text { Load Profile }\end{array}$ & $\begin{array}{l}\text { DOE Commercial } \\
\text { Reference Buildings }\end{array}$ & Building type & Medium office \\
\hline Utility Rate & $\underline{U R D B}$ & $\begin{array}{l}\text { Utility and customer } \\
\text { type }\end{array}$ & $\begin{array}{l}\text { Xcel General Service } \\
\text { (A14) Secondary } \\
\text { Voltage }\end{array}$ \\
\hline $\begin{array}{l}\text { EV Load } \\
\text { Profile }\end{array}$ & $\underline{\text { EVI-Pro }}$ & $\begin{array}{l}\text { Number of charges/day; } \\
\text { level of charging }\end{array}$ & $\begin{array}{l}\text { Level } 2 \text { workplace } \\
\text { charging }\end{array}$ \\
\hline
\end{tabular}

This analysis considers the economics of solar PV, battery storage, and electric vehicle loads for a representative office building in Minneapolis, MN, under Xcel General Service (A14) Secondary Service rate. The results are not representative of other locations, building loads, or rate structures. 


\section{Xcel - General Service (A14) Secondary Voltage}

\begin{tabular}{|c|c|c|c|}
\hline & $\$ / \mathbf{k W h}$ & $\$ / \mathrm{kW}$ & $\$ /$ month \\
\hline Customer Charge & & & $\$ 25.64$ \\
\hline Demand Charge & & $\begin{array}{l}\text { \$10.71 Oct. - May } \\
\text { \$15.25 Jun. - Sep. }\end{array}$ & \\
\hline Energy Charge & $\$ 0.03498$ & & \\
\hline Fuel Adjustment Factor & $\$ 0.02676$ & & \\
\hline Total & $\$ 0.061740$ & $\begin{array}{l}\text { \$10.71 Oct. - May } \\
\text { \$15.25 Jun. - Sep. }\end{array}$ & $\$ 25.64$ \\
\hline
\end{tabular}

Additional attributes of the selected rate include:

- In no month shall the demand to be billed be considered as less than current month's adjusted demand in $\mathrm{kW}$ or $50 \%$ of the greatest monthly adjusted demand in kW during the preceding 11 months

- Does not include environmental improvement rider or resource adjustment

- Fuel adjustment factor for C\&I demand non-TOD

- For more information visit: https://www.xcelenergy.com/staticfiles/xe/Regulatory/Regulatory\%20PDFs/rates/MN/Me Section 5.pdf 


\section{Building Load Profile vs. PV Output}

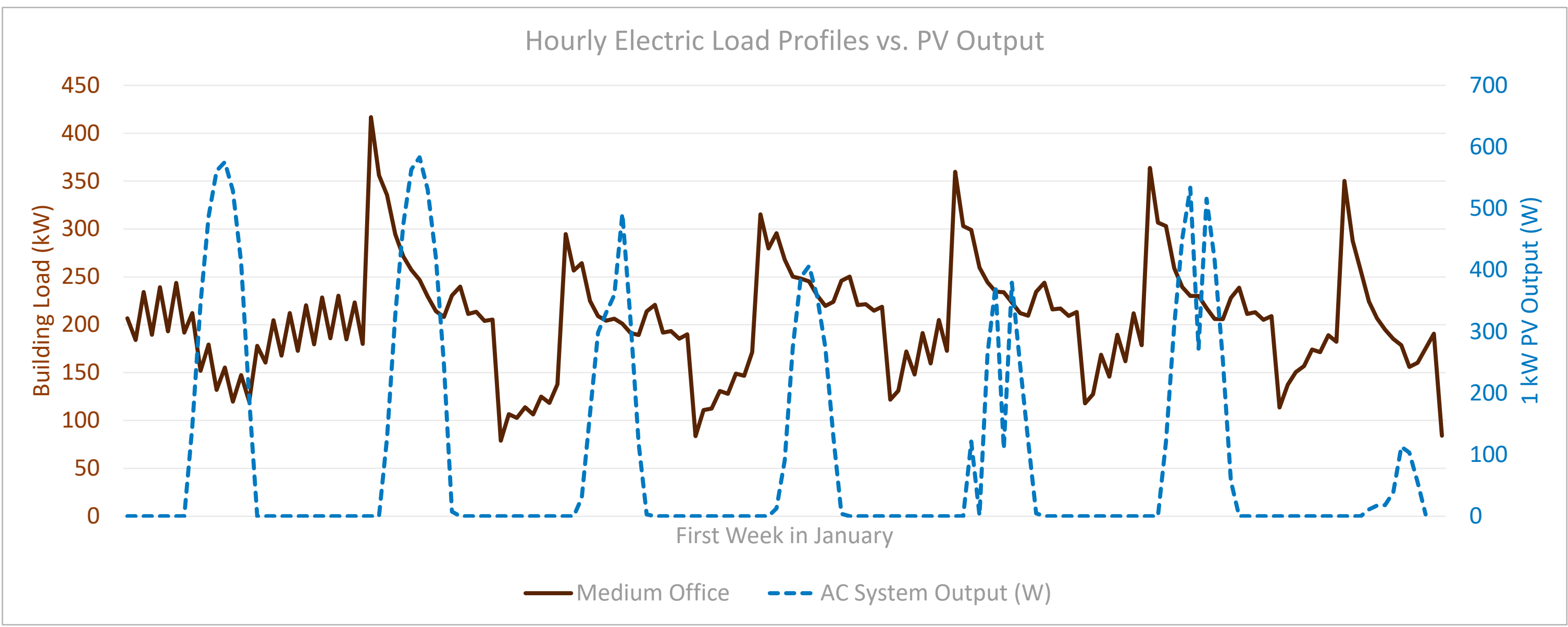

This chart shows the load profile of a medium-sized office (based on DOE Commercial Reference Building database) and PV system output for an illustrative week in January. 


\section{EV Load Input for Static Load Profile}

\section{Load Data for 6 EV Chargers - First Week of January}

25

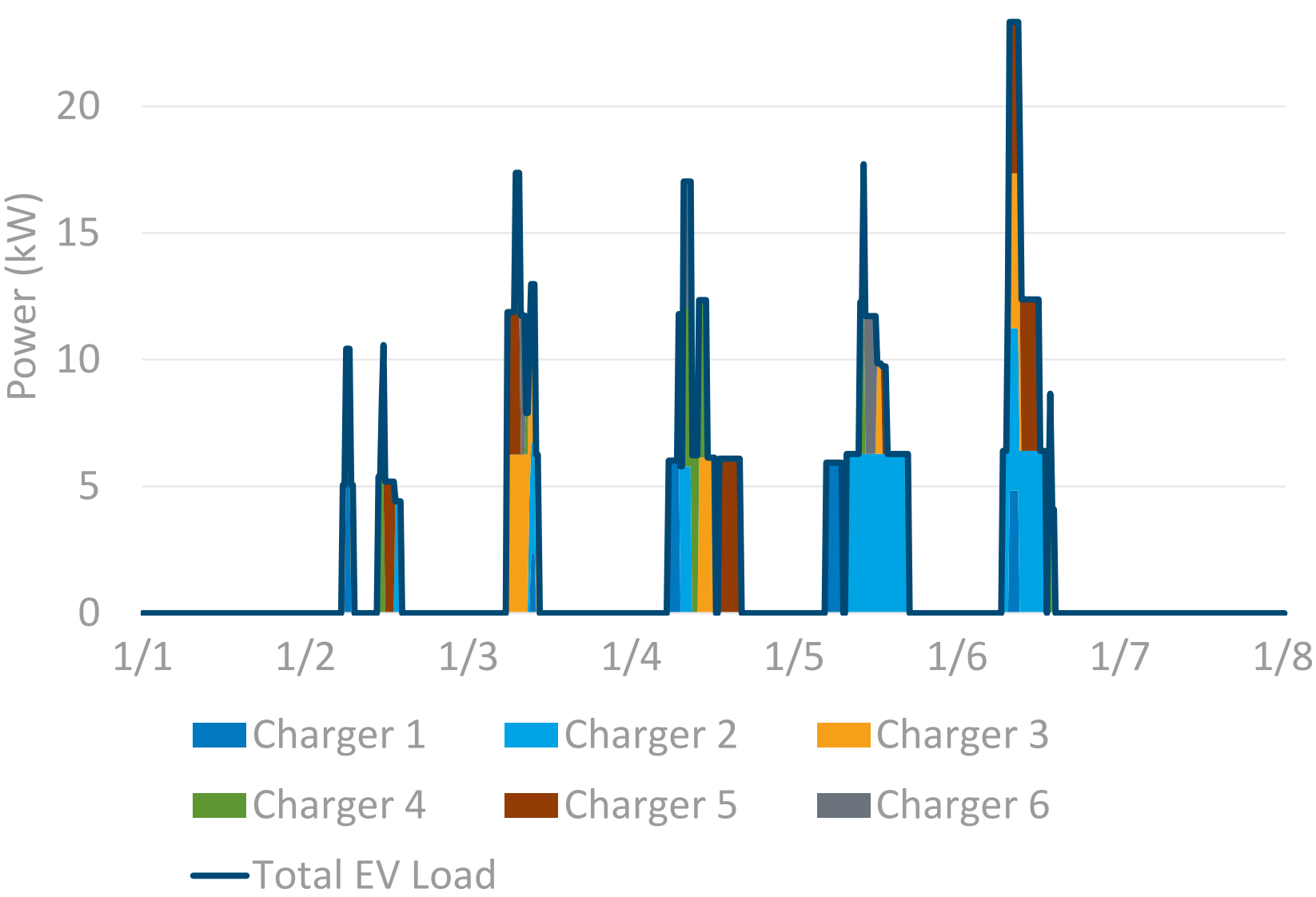

This chart shows the loads of the six chargers (each represented as its own color) over the course of a week in January. This evaluation of workplace charging assumed that charging only occurred on weekdays.
- NREL'S EVI-Pro database was used to generate the EV load profiles; the EVI-pro database provides simulated vehicle arrival and departure times (at the EV charging station), and energy (kWh) requirements.

- This analysis considers (6) $6.6 \mathrm{~kW}$ EV chargers, located at an office building.

- For the static loads (i.e., without smart or managed charging), it was assumed that the EVs would start charging at the arrival time, and continue charging $(6.6 \mathrm{~kW})$ at the maximum rated power of the charge until the energy requirement was met.

- For the flexible (or smart/managed) charging loads, the daily arrival and departure time, and energy requirement were entered into REopt; the model determined at what level the EVs were charged (between 0 and $6.6 \mathrm{~kW}$ ) throughout the day, such that the energy requirement was met by the departure time and lifecycle costs were minimized. 


\section{Building and EV Load}

Medium Office vs. EV Load - First Week of January

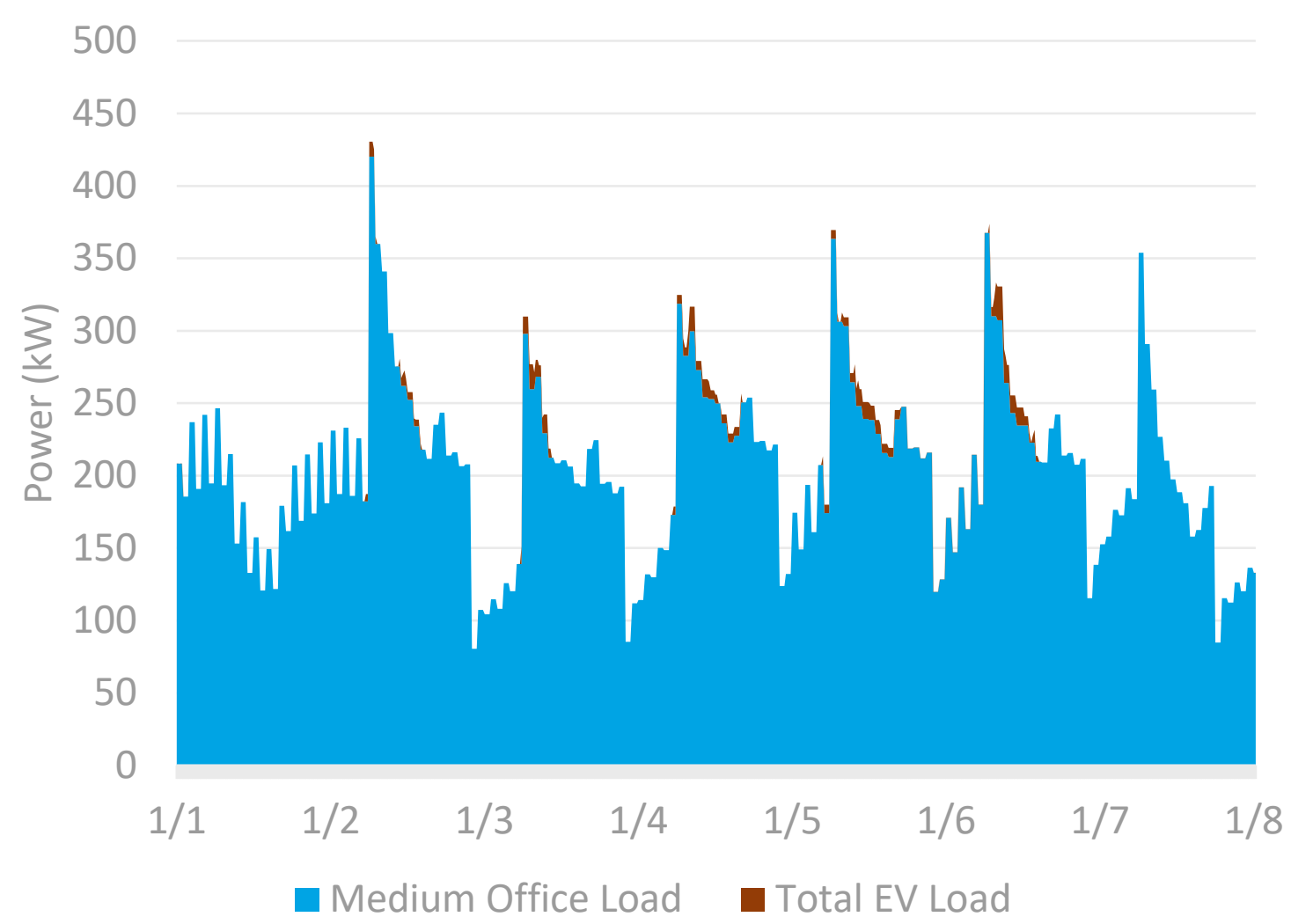

Medium Office vs. EV Load - First Week in July

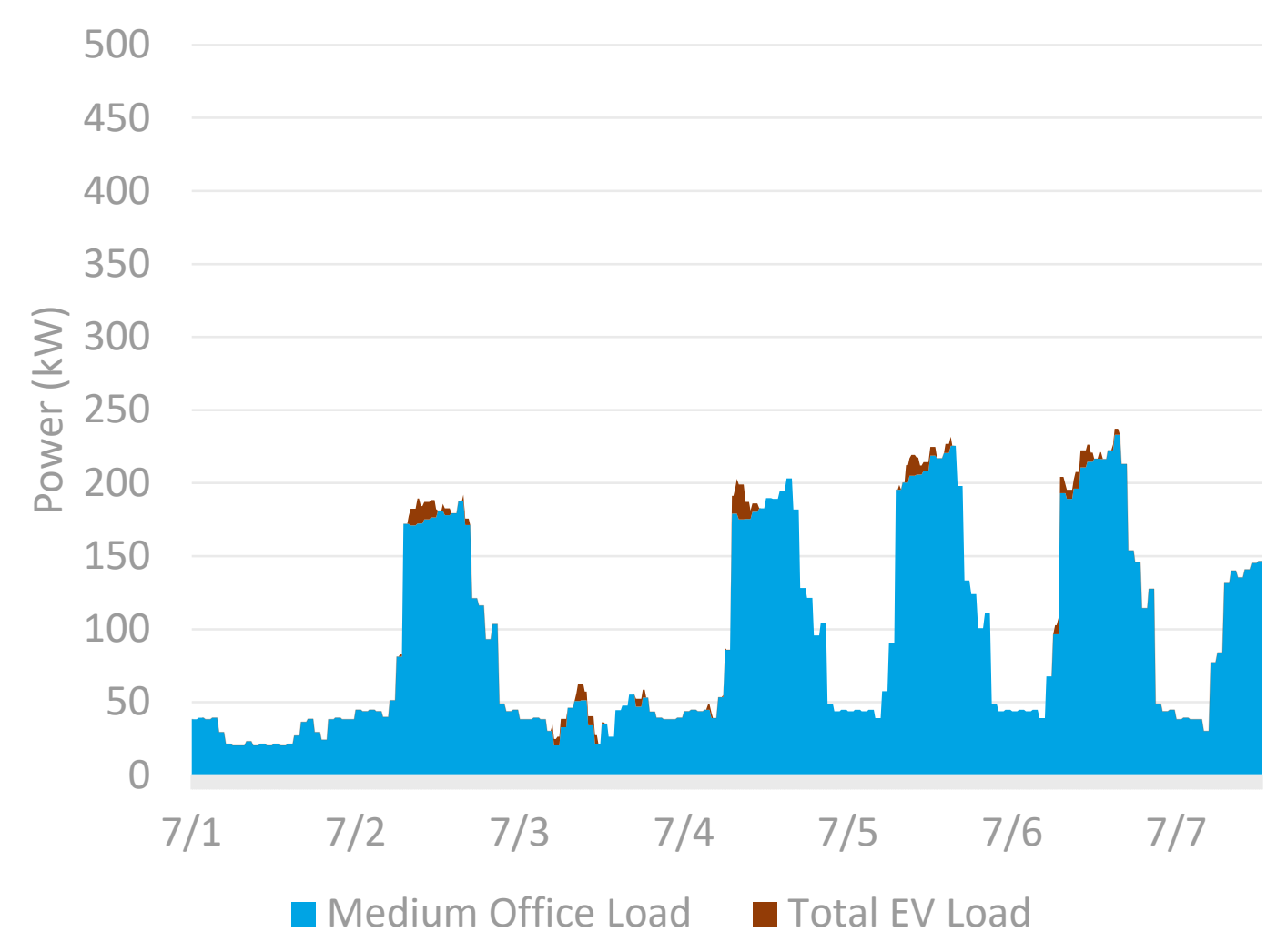

These charts show the static EV charging load (red) layered on top of the medium office load (in blue) for a week in January and a week in July. 


\section{EV Charging Profile vs. PV Output}

\section{EV Total Load vs. PV Output}

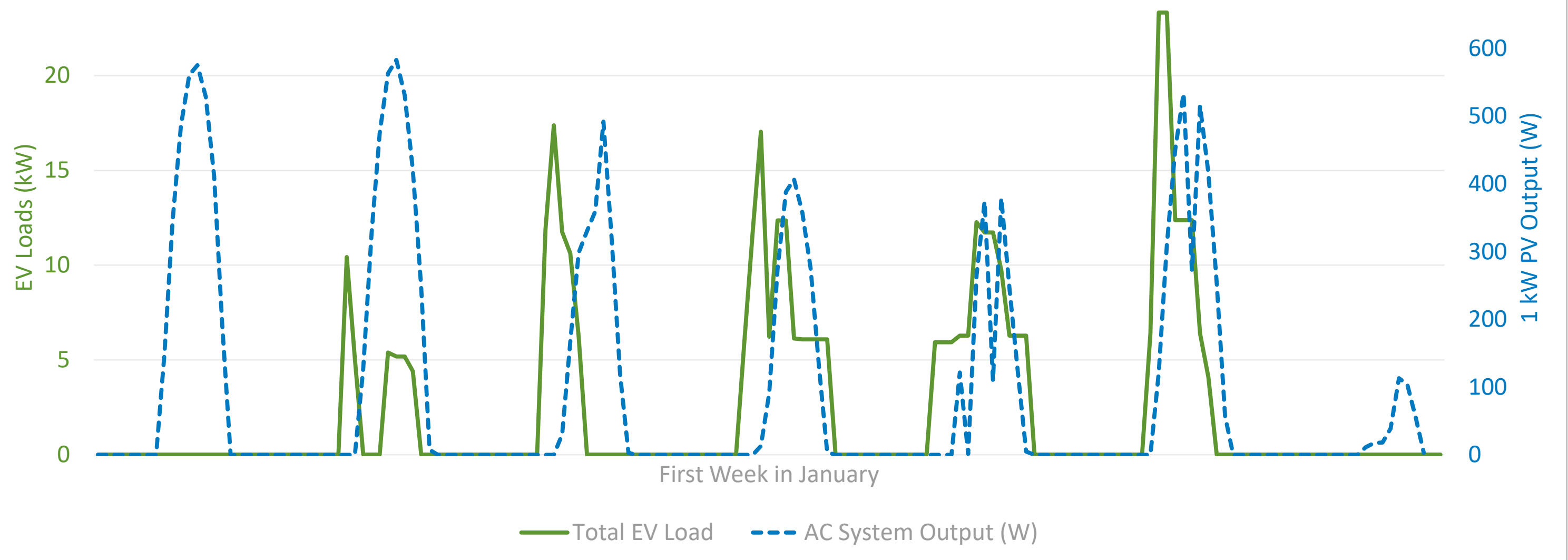

These charts show the EV loads from the six chargers (shown aggregated as a single load) and the PV system output for a week in January. 


\section{Other Analysis Assumptions}

\begin{tabular}{ll}
\hline Input & Assumption \\
\hline Technologies & EV, solar PV, battery storage (depending on scenario) \\
Objective & Minimize lifecycle cost (cost-effective projects) \\
\hline Ownership model & $3^{\text {rd }}$ party financed \\
Analysis period & 25 years \\
Discount rate & $3 \%$ for site/8.1\% for developer \\
Escalation rate & $2.60 \%$ per EIA utility cost escalation rates \\
Inflation rate & $2.1 \%$ per EIA \\
Incentives & $30 \%$ ITC; 5 year MACRS for PV \& storage (storage not charging from grid) \\
\hline Net metering & None \\
Electricity sellback rate & $\$ 0 / k W h$ \\
Interconnection limit & None \\
Technology costs & PV: \$2.00/W ground mount installed; \$15.50/kW/yr. O\&M \\
& Storage: \$500/kWh and \$1000/kW; replacement costs in year 10: \\
\hline Technology resource & $\$ 230 / \mathrm{kWh}$ and \$460/kW \\
Area for PV & TMY3 Weather Data \\
\hline
\end{tabular}




\section{Analysis Explored}

- Specifically, this analysis will explore:

1. How can PV and stationary storage be co-deployed with EV charging infrastructure to lower the cost of purchasing grid electricity?

2. What are the potential savings of co-locating EV charging infrastructure with (behind the meter of) a commercial building?

3. What savings can be gained from optimizing the times at which the EVs are charged?

4. What savings can be gained from optimizing the times at which the EVs are charged when co-located with a commercial building? 


\section{How can PV and stationary storage be co-deployed with EV charging infrastructure to lower the cost of purchasing grid electricity?}

NREL evaluated the following scenarios:

- EV charging load only: The cost of electricity for the load of the six EV chargers, assuming all electricity is purchased from the utility

- EV charging load with PV + storage: The minimum lifecycle cost of electricity for the load of the EV chargers assuming electricity can be purchased from the utility, and that PV and stationary storage can be deployed to mitigate these costs if they are cost-effective

- Sensitivity: The following sensitivity analyses were conducted:

- Impact of higher solar PV prices

- Impact of a utility rate with lower demand charges

- Impact of fewer EV chargers 


\section{Results}

\begin{tabular}{rrr} 
Scenario & $\begin{array}{r}\text { EV Chargers } \\
\text { Only }\end{array}$ & $\begin{array}{r}\text { Chargers } \\
+ \text { PV and } \\
\text { Storage }\end{array}$ \\
PV Size (kW) & 0 & 9 \\
Battery Size (kW) & 0 & 17 \\
Battery Size (kWh) & 0 & 28 \\
Total Capital Cost (\$) & $\$ 0$ & $\$ 49,100$ \\
Electricity Purchases (kWh) & 17,400 & 9,100 \\
Percent RE (\%) & $0 \%$ & $64 \%$ \\
Year 1 Energy Costs (\$) & $\$ 1,100$ & $\$ 600$ \\
Year 1 Demand Costs (\$) & $\$ 4,500$ & $\$ 2,000$ \\
Year 1 Fixed Costs (\$) & $\$ 300$ & $\$ 300$ \\
\hline Year 1 Total Electricity Cost (\$) & $\$ 5,900$ & $\$ 2,800$ \\
\hline 25 Year Lifecycle Cost (\$) & $\$ 140,000$ & $\$ 118,000$ \\
\hline Net Present Value (NPV) (\$) & $\$ 0$ & $\$ 21,000$ \\
\hline
\end{tabular}

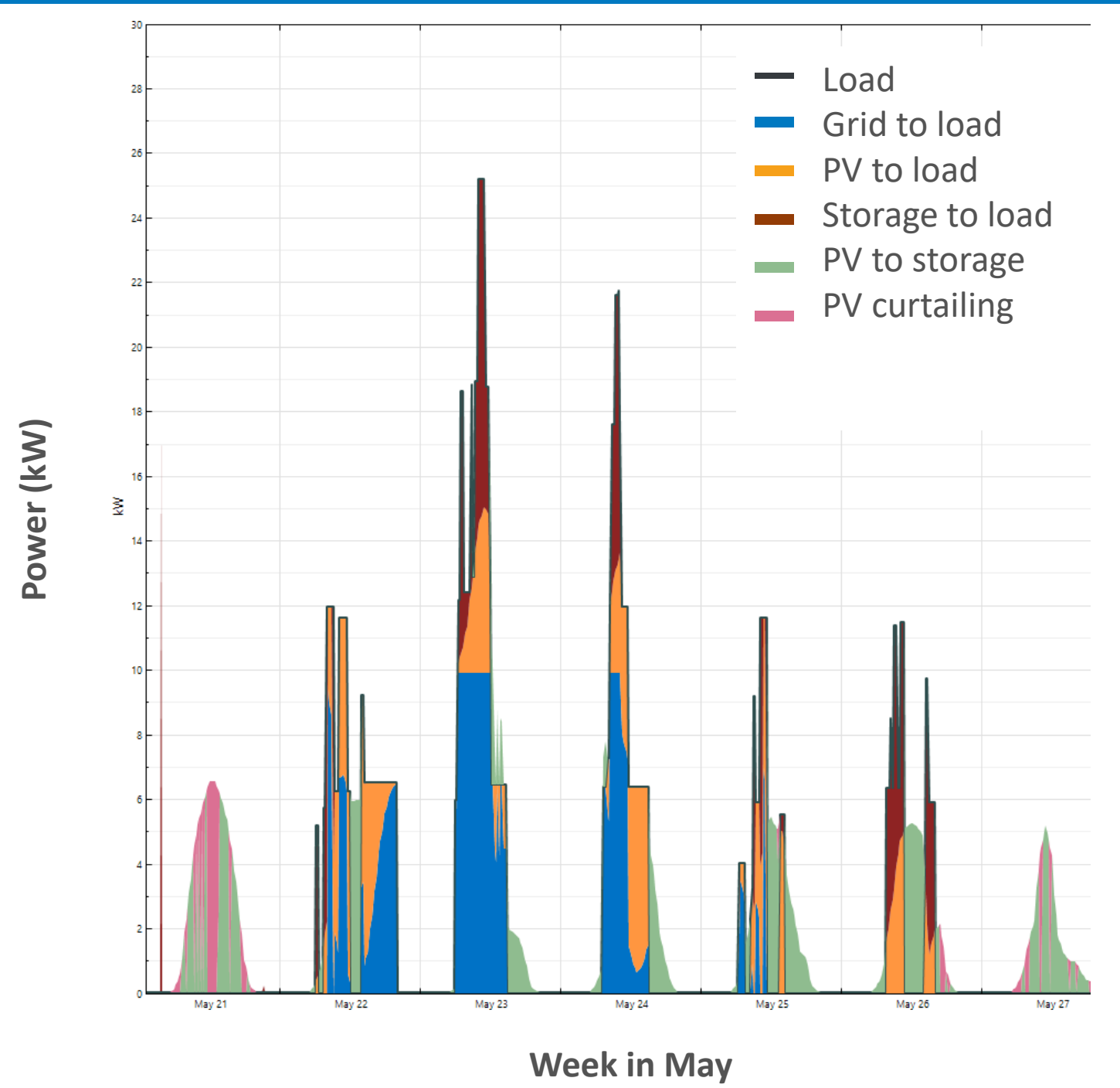

Results show that under NM Xcel A14, PV and battery storage can be used to mitigate the cost of the electric load from charging the EVs by offsetting both energy and demand costs. 


\section{Results (continued)}

\begin{tabular}{|c|c|c|c|c|c|c|c|}
\hline \multicolumn{2}{|l|}{ Sensitivity Scenario } & Base Case & $\begin{array}{l}\text { Increase } \\
\text { Solar Cost }\end{array}$ & \multicolumn{2}{|c|}{$\begin{array}{r}\text { Lower Demand } \\
\text { Charge }\end{array}$} & \multicolumn{2}{|c|}{ Fewer EV Chargers } \\
\hline Technology Options & Grid Only & $\begin{array}{r}\text { Grid, PV, } \\
\text { Storage }\end{array}$ & $\begin{array}{r}\text { Grid, PV, } \\
\text { Storage }\end{array}$ & Grid Only & $\begin{array}{r}\text { Grid, PV, } \\
\text { Storage }\end{array}$ & $\begin{array}{l}\text { Grid } \\
\text { Only }\end{array}$ & $\begin{array}{r}\text { Grid, PV, } \\
\text { Storage }\end{array}$ \\
\hline PV Size (kW) & 0 & 9 & 4 & 0 & 3 & 0 & 5 \\
\hline Battery Size (kW) & 0 & 17 & 16 & 0 & 7 & 0 & 10 \\
\hline Battery Size (kWh) & 0 & 28 & 26 & 0 & 7 & 0 & 17 \\
\hline Total Capital Cost (\$) & $\$ 0$ & $\$ 49,100$ & $\$ 41,000$ & $\$ 0$ & $\$ 16,500$ & $\$ 0$ & $\$ 28,600$ \\
\hline Electricity Purchases (kWh) & 17,400 & 9,100 & 12,700 & 17,400 & 14,400 & 8,700 & 4,200 \\
\hline Percent RE (\%) & $0 \%$ & $64 \%$ & $31 \%$ & $0 \%$ & $24 \%$ & $0 \%$ & $76 \%$ \\
\hline Year 1 Energy Costs (\$) & $\$ 1,100$ & $\$ 600$ & $\$ 800$ & $\$ 1,300$ & $\$ 1,100$ & $\$ 500$ & $\$ 300$ \\
\hline Year 1 Demand Costs (\$) & $\$ 4,500$ & $\$ 2,000$ & $\$ 2,200$ & $\$ 2,400$ & $\$ 1,800$ & $\$ 2,700$ & $\$ 1,200$ \\
\hline Year 1 Fixed Costs (\$) & $\$ 300$ & $\$ 300$ & $\$ 300$ & $\$ 300$ & $\$ 300$ & $\$ 300$ & $\$ 300$ \\
\hline Year 1 Total Electricity Cost (\$) & $\$ 5,900$ & $\$ 2,800$ & $\$ 3,300$ & $\$ 4,000$ & $\$ 3,200$ & $\$ 3,600$ & $\$ 1,800$ \\
\hline 25 Year Lifecycle Cost (\$) & $\$ 140,000$ & $\$ 118,000$ & $\$ 122,000$ & $\$ 96,000$ & $\$ 93,000$ & $\$ 85,000$ & $\$ 73,000$ \\
\hline NPV (\$) & $\$ 0$ & $\$ 21,000$ & $\$ 18,000$ & $\$ 0$ & $\$ 2,000$ & $\$ 0$ & $\$ 11,000$ \\
\hline
\end{tabular}

- Sensitivity analysis shows that the recommended solar PV system size is decreased when the:

- Installed cost of PV increases from $\$ 2 / \mathrm{W}$ to $\$ 3 / \mathrm{W}$; the size of battery storage also decreases, but not as much

- The rate has a demand charge of $\$ 6.50$ instead of $\$ 10-15 / \mathrm{kW}$; the size of battery decreases more so than the size of the PV system

- The number of EV chargers is reduced from 6 to 3; the PV and storage size both decrease proportionally

As in the prior slide, the size of PV and/storage system that the model suggests is based on seeking to minimize the 25-year lifecycle cost. The Increase Solar Cost NPV is relative to the Grid Only Base Case, all others are relative to the Grid Only option within their scenario. 


\section{What are the potential savings of co-locating EV charging infrastructure with (behind the meter of) a commercial building?}

NREL evaluated the following scenarios:

- Building + EV charging load: The cost of electricity for the load of the commercial building and the EV chargers (when billed separately, behind two separate meters), assuming all electricity is purchased from the utility.

- Building + EV charging combined load: The cost of electricity for the load of the commercial building and the EV chargers (as one load, behind the same meter), assuming all electricity is purchased from the utility.

- Building + EV charging load with PV + storage: The minimum lifecycle cost of electricity for the load of the commercial building and the EV chargers (as one load, behind the same meter), assuming electricity can be purchased from the utility and that PV and stationary storage can be deployed to mitigate these costs if costeffective. 


\section{Results}

\begin{tabular}{|c|c|c|c|c|c|}
\hline Scenario & $\begin{array}{r}\text { EV Chargers } \\
\text { Only }\end{array}$ & $\begin{array}{r}\text { Building } \\
\text { Only }\end{array}$ & $\begin{array}{r}\text { Building + } \\
\text { EV Chargers } \\
\text { (Separate } \\
\text { Meters) }\end{array}$ & $\begin{array}{r}\text { Building + } \\
\text { EV Chargers } \\
\text { (Combined } \\
\text { Meter) }\end{array}$ & $\begin{array}{r}\text { Building + EV } \\
\text { Chargers } \\
\text { (Combined } \\
\text { Meter) } \\
\text { Add PV + } \\
\text { Storage }\end{array}$ \\
\hline PV Size (kW) & 0 & 0 & 0 & 0 & 155 \\
\hline Battery Size (kW) & 0 & 0 & 0 & 0 & 66 \\
\hline Battery Size (kWh) & 0 & 0 & 0 & 0 & 77 \\
\hline Total Capital Cost (\$) & $\$ 0$ & $\$ 0$ & $\$ 0$ & $\$ 0$ & $\$ 416,100$ \\
\hline Electricity Purchases (kWh) & 17,400 & $1,022,700$ & $1,040,100$ & $1,040,100$ & 852,100 \\
\hline Percent RE (\%) & $0 \%$ & $0 \%$ & $0 \%$ & $0 \%$ & $19 \%$ \\
\hline Year 1 Energy Costs (\$) & $\$ 1,100$ & $\$ 63,100$ & $\$ 64,200$ & $\$ 64,200$ & $\$ 52,600$ \\
\hline Year 1 Demand Costs (\$) & $\$ 4,500$ & $\$ 42,900$ & $\$ 47,400$ & $\$ 43,700$ & $\$ 35,100$ \\
\hline Year 1 Fixed Costs (\$) & $\$ 300$ & $\$ 300$ & $\$ 600$ & $\$ 300$ & $\$ 300$ \\
\hline Year 1 Total Electricity Cost (\$) & $\$ 5,900$ & $\$ 106,400$ & $\$ 112,200$ & $\$ 108,200$ & $\$ 88,000$ \\
\hline 25 Year Lifecycle Cost (\$) & $\$ 140,000$ & $\$ 2,529,000$ & $\$ 2,669,000$ & $\$ 2,573,000$ & $\$ 2,494,000$ \\
\hline NPV (\$) & - & - & $\$ 0$ & $\$ 96,000$ & $\$ 79,000$ \\
\hline
\end{tabular}

If the EV and building load were billed under the same meter, demand costs and fixed costs could be decreased (by $\$ 96,000$ )

- The demand charges are reduced because the peak load of the building is not aligned with the peak load of the EV chargers

- The fixed charges are reduced because they are billed per meter

- PV and storage can reduce the cost of the combined building and EV load

The NPV for the Building + EV Chargers (Combined Meter) is relative to Building + EV Chargers (Separate Meters). The NPV for the Building + EV Chargers (Combined Meter) Add PV+Storage is relative to the Building + EV Chargers (Combined Meter). 


\section{Results (continued)}

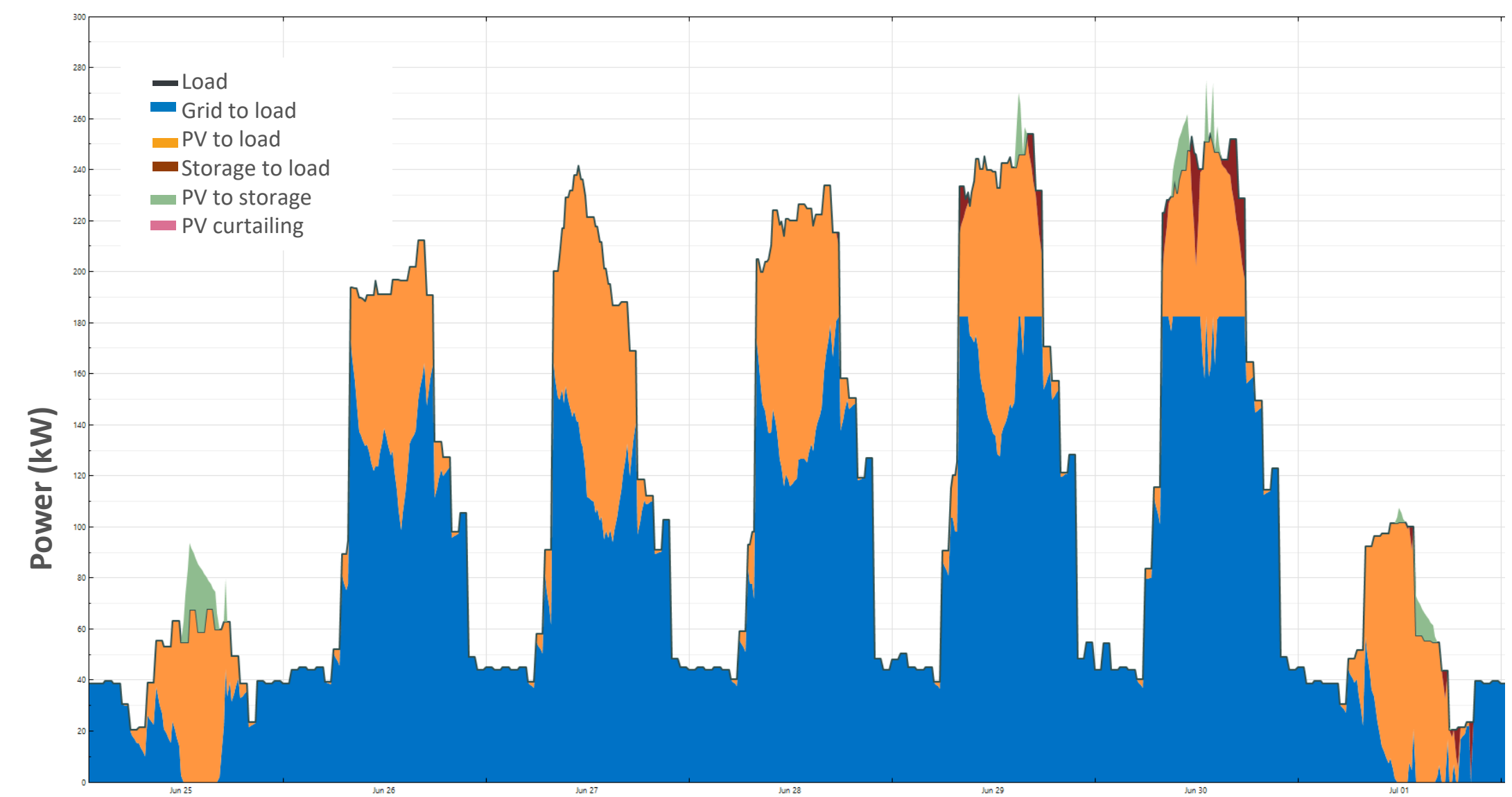

Week in June
- Dispatch shows the solar PV offsetting energy charges and demand.

- The relatively small storage system is dispatched to mitigate the variability of PV, especially during early morning/late evening. 


\section{What savings can be gained from optimizing the times at which the EVs are charged?}

NREL evaluated the following scenarios:

- Static EV charging load only: The cost of electricity is calculated for the load of the six EV chargers, assuming all electricity is purchased from the utility. Charging starts when vehicles arrive and continues at a constant rate until a vehicle's battery is full.

- Flexible EV charging load only: The cost of electricity is calculated for the load of the EV chargers, assuming all electricity is purchased from the utility. Charging of the EVs is flexible within specified parameters (e.g., the rating of the charger and the energy needs for the vehicles each day based on EVI-Pro modeling).

- Flexible EV charging load with PV + storage: The cost of electricity is calculated for the load of the EV chargers, assuming electricity can be purchased from the utility. PV and stationary storage can be deployed to mitigate these costs if cost-effective. Charging of the EVs is flexible within specified parameters and can be managed to decrease lifecycle cost taking all loads, generation, and storage sources into account. 


\section{Results}

\begin{tabular}{|c|c|c|c|c|}
\hline Scenario & $\begin{array}{r}\text { EV Chargers Only } \\
\text { (Static Load) }\end{array}$ & $\begin{array}{r}\text { EV Chargers Only } \\
\text { (Flexible Load) }\end{array}$ & $\begin{array}{r}\text { EV Chargers Only } \\
\text { (Flexible Load) Add } \\
\text { PV + Storage }\end{array}$ & $\begin{array}{r}\text { EV Chargers Only } \\
\text { (Flexible Load) Add } \\
\text { PV + Storage } \\
50 \% \text { Cost Reduction }\end{array}$ \\
\hline PV Size (kW) & 0 & 0 & 0 & 13 \\
\hline Battery Size (kW) & 0 & 0 & 0 & 0 \\
\hline Battery Size (kWh) & 0 & 0 & 0 & 0 \\
\hline Total Capital Cost (\$) & $\$ 0$ & $\$ 0$ & $\$ 0$ & $\$ 15,000$ \\
\hline Electricity Purchases (kWh) & 17,400 & 17,400 & 17,400 & 6,600 \\
\hline Percent RE (\%) & $0 \%$ & $0 \%$ & $0 \%$ & $62 \%$ \\
\hline Year 1 Energy Costs (\$) & $\$ 1,100$ & $\$ 1,100$ & $\$ 1,100$ & $\$ 400$ \\
\hline Year 1 Demand Costs (\$) & $\$ 4,500$ & $\$ 1,400$ & $\$ 1,400$ & $\$ 900$ \\
\hline Year 1 Fixed Costs (\$) & $\$ 300$ & $\$ 300$ & $\$ 300$ & $\$ 300$ \\
\hline Year 1 Total Electricity Cost (\$) & $\$ 5,900$ & $\$ 2,800$ & $\$ 2,800$ & $\$ 1,600$ \\
\hline 25 Year Lifecycle Cost (\$) & $\$ 140,000$ & $\$ 67,000$ & $\$ 67,000$ & $\$ 57,000$ \\
\hline NPV (\$) & $\$ 0$ & $\$ 73,000$ & $\$ 0$ & $\$ 10,000$ \\
\hline
\end{tabular}

The NPV for EV Chargers Only (Flexible Load) is relative to EV Chargers Only (Static Load). The NPV for EV Chargers Only (Flexible Load) Add PV+ Storage 50\% Cost Reduction is relative to EV Chargers Only (Flexible Load) Add PV + Storage and assumes 50\% capital cost reduction for PV and Storage 


\section{Results (continued)}

\section{Flexible vs. Static Load}

25

20

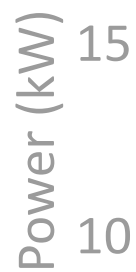

5

0

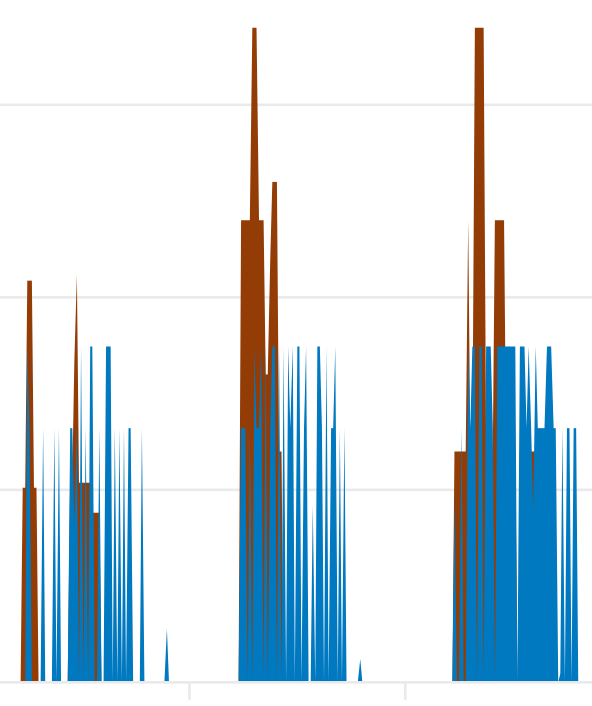

$1 / 3$

$1 / 4$

$1 / 5$

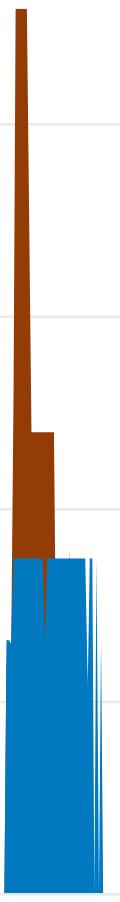

$1 / 6$
$1 / 7$
- When the model is allowed to determine how the EVs should be charged (flexible EV load), the load is spread out throughout the day, lowering the peak demand.

- As a result, the demand charges are lowered from $\$ 4,500$ to $\$ 1,400$ in year 1 (energy and fixed charges are not impacted).

- $\quad$ Adding PV and/or storage (at current costs) to the flexible EV load only (no building load) does not appear cost effective, as the "peakiness" of the load has been mitigated, and a larger (longer duration), more expensive, battery would need to be installed to further reduce the demand and cost. 


\section{Results (continued)}

20

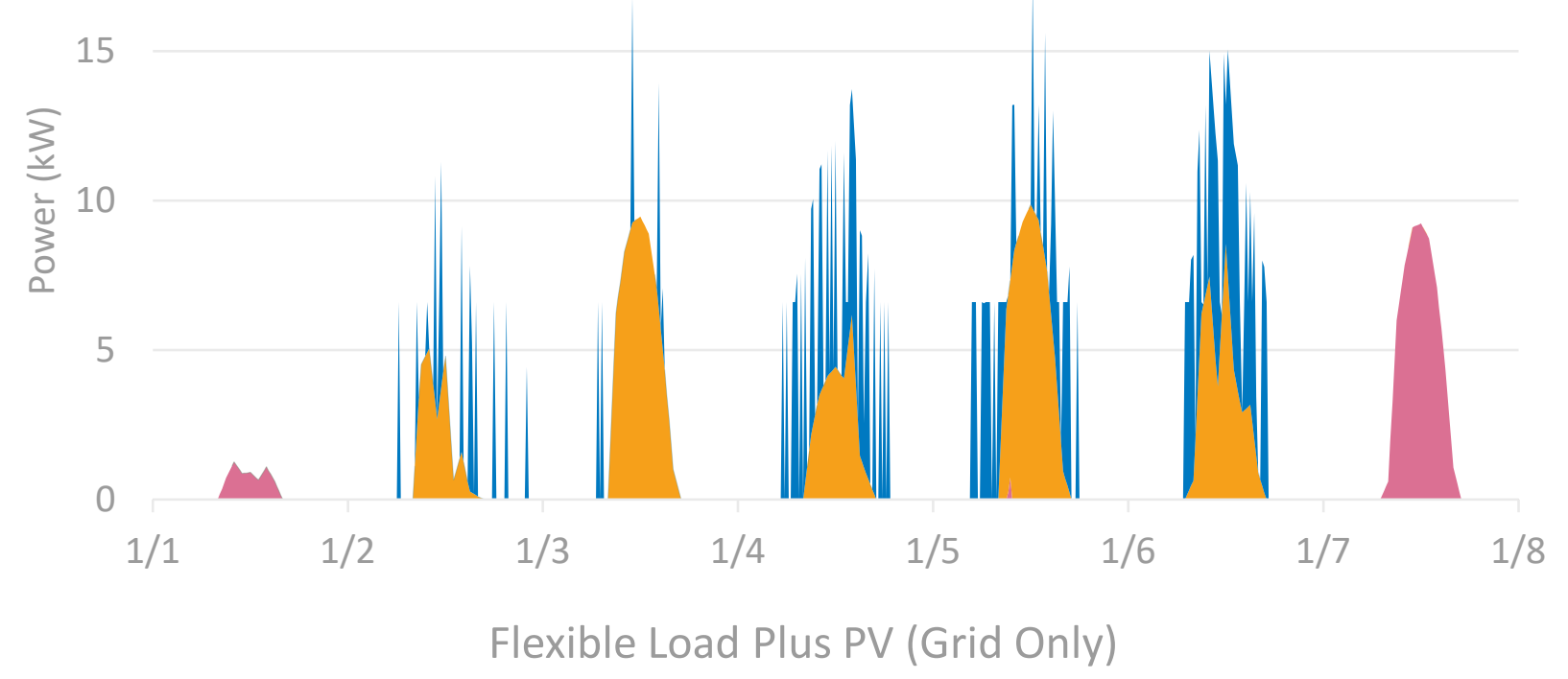

20

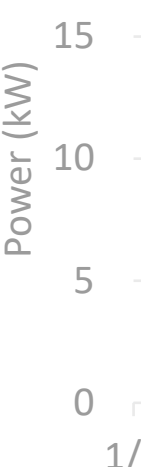

Flexible Load Plus PV

- PV Exporting/Curtailing

PV to EV

- Grid to EV

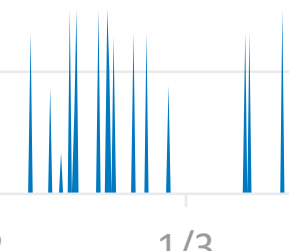

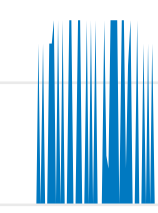

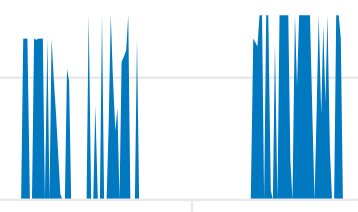

- When battery storage and PV capital costs are reduced by $50 \%$, a 13 kW PV system appears cost effective, lowering both energy and demand charges.

- In this scenario, the PV system is serving the EV load during the day, and the EV load is being shifted to fit under the PV generation.

- In this scenario, battery storage does not appear cost effective. The EV load flexibility is serving the same purpose as stationary storage, as the charging can be modified to mitigate demand charges. 


\section{What savings can be gained from optimizing the times at which the EVs are charged when co-located with a commercial building?}

NREL evaluated the following scenarios:

- Building + static EV charging load: The cost of electricity is calculated for the load of the commercial building and the EV chargers (as one load, behind the same meter), assuming all electricity is purchased from the utility. Charging starts when the a vehicle arrives, and continues at a constant rate until the battery is full.

- Building + flexible EV charging load: The cost of electricity is calculated for the load of the commercial building and the EV chargers (as one load, behind the same meter), assuming all electricity is purchased from the utility. EV Charging is flexible within specified parameters.

- Building + flexible EV charging load with PV + storage: The cost of electricity is calculated for the load of the commercial building and the EV chargers, assuming electricity can be purchased from the utility. PV and stationary storage can be deployed to mitigate these costs if cost-effective. EV charging is flexible within specified parameters. 


\section{Results}

\begin{tabular}{|c|c|c|c|}
\hline Scenario & $\begin{array}{r}\text { Building + EV } \\
\text { Chargers } \\
\text { (Combined } \\
\text { Meter Static EV } \\
\text { Load) }\end{array}$ & $\begin{array}{r}\text { Building + EV } \\
\text { Chargers } \\
\text { (Combined Meter) } \\
\text { Flexible EV Load }\end{array}$ & $\begin{array}{r}\text { Building + EV } \\
\text { Chargers } \\
\text { (Combined } \\
\text { Meter) Flexible } \\
\text { EV Load } \\
\text { Add PV + Storage }\end{array}$ \\
\hline PV Size (kW) & 0 & 0 & 211 \\
\hline Battery Size (kW) & 0 & 0 & 60 \\
\hline Battery Size (kWh) & 0 & 0 & 71 \\
\hline Total Capital Cost (\$) & $\$ 0$ & $\$ 0$ & $\$ 521,000$ \\
\hline Electricity Purchases (kWh) & $1,040,100$ & $1,040,100$ & 791,692 \\
\hline Percent RE (\%) & $0 \%$ & $0 \%$ & $26 \%$ \\
\hline Year 1 Energy Costs (\$) & $\$ 64,200$ & $\$ 64,200$ & $\$ 48,900$ \\
\hline Year 1 Demand Costs (\$) & $\$ 43,700$ & $\$ 43,000$ & $\$ 33,400$ \\
\hline Year 1 Fixed Costs (\$) & $\$ 300$ & $\$ 300$ & $\$ 300$ \\
\hline Year 1 Total Electricity Cost (\$) & $\$ 108,200$ & $\$ 107,400$ & $\$ 82,500$ \\
\hline 25 Year Lifecycle Cost (\$) & $\$ 2,573,000$ & $\$ 2,554,000$ & $\$ 2,458,000$ \\
\hline NPV (\$) & $\$ 0$ & $\$ 19,000$ & $\$ 96,000$ \\
\hline
\end{tabular}

- When PV and storage is evaluated at the office building along with the flexible EV load, the optimal size of PV is larger, and the optimal size of storage is smaller, compared to the same scenario with the static EV load.

- The EV load flexibility is serving the same purpose as stationary storage, as the charging can be modified to mitigate demand charges.

- Because of this, additional PV is cost effective, because the flexible EV load enables it to shave a wider part of the demand peak. 


\section{Conclusions}

- Three different ways of mitigating the cost of EV charging stations were explored:

- Adding PV + Storage

- Co-locating with a commercial building

- Optimizing the times at which the EVs were charged.

- Under the rate tariff, building and EV load, solar resource, and other assumptions specific to this analysis, all three mitigation options result in savings.

- When considering the load of the EV chargers only, optimizing the times at which the EVs were charged provided more potential savings than deploying PV + storage because the flexibility of EV charging serves the same function as adding battery storage, but at a lower (no) cost.

- Combining the load of the EV charges with a commercial building provided both demand and fixed cost savings.

- In this scenario, the flexibility of EV charging had less of an impact, likely due to the demand of the EV chargers not coinciding with that of the building in the first place.

- In either scenario (flexible or static load EV charging), PV and storage can mitigate the cost of the total electric load. 
Appendix 


\section{REopt Platform: Decision Support through the Energy Planning Process}

\section{Optimization • Integration • Automation}

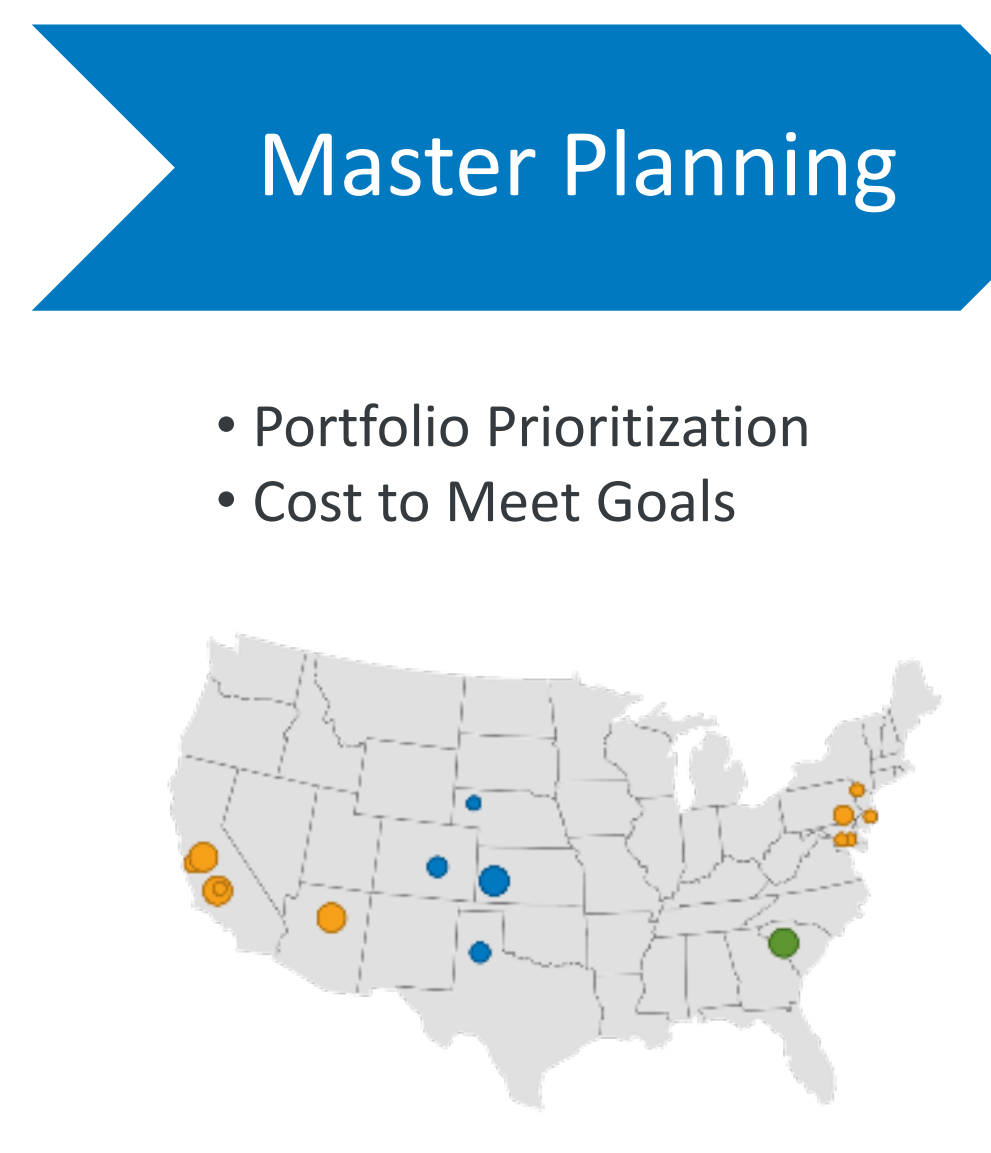

Cost-effective RE at Army bases
Economic Dispatch

- Technology Types \& Sizes

- Optimal Operating Strategies

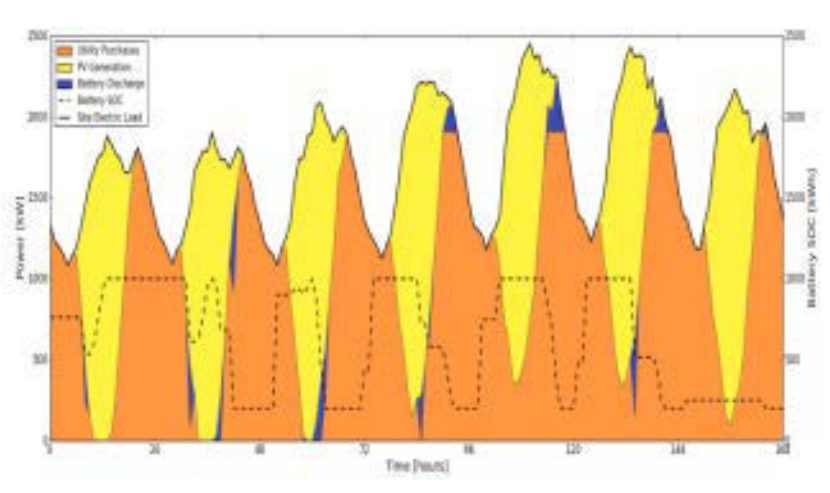

Cost-Optimal Operating Strategy
Resiliency Analysis

- Microgrid Dispatch

- Energy Security Evaluation

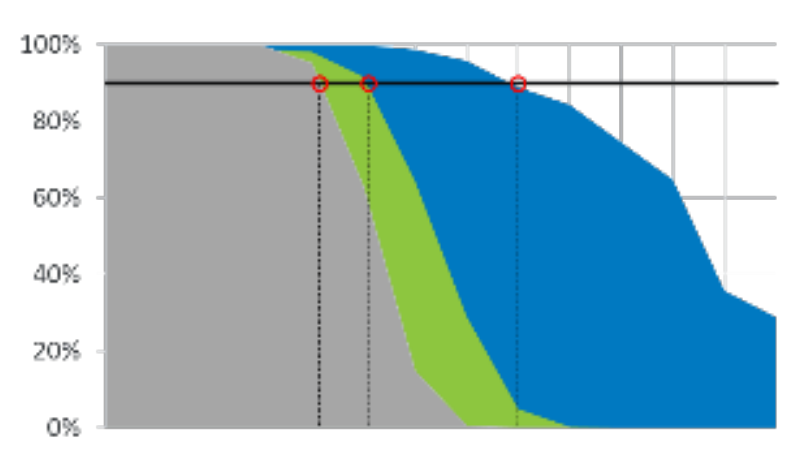

Extending Resiliency with Renewable Energy 


\section{REopt PV and Battery Assumptions}

- Solar PV

- Fixed tilt; oriented due south with tilt = latitude

- Hourly solar radiation data from Typical Meteorological Year 3 (NREL 2008). Represents 1,020 locations in the US. Derived from 1991-2005 National Solar Radiation Data Base.

\section{Solar PV Characteristics}

Annual Degradation (\%)

$-0.5 \%$

Inverter Efficiency (\%)

$96 \%$

BOS Efficiency
- Li-lon battery technology

- Bucket model moves energy from one time period to another

- Sizes energy capacity / power independently

- Tracks and costs battery degradation

- Simple throughput

- Cycles

- Cycles / Depth of Discharge

\begin{tabular}{lc}
\hline Li Ion Battery Characteristics & \\
\hline Total Round Trip Efficiency & $89.9 \%$ \\
\multicolumn{1}{l}{ Battery Throughput } & $97.5 \%$ \\
Inverter Efficiency & $96 \%$ \\
\hline Rectifier Efficiency & $96 \%$ \\
Minimum Charge & $0 \%$ \\
\hline Initial SOC & $0 \%$ \\
\hline
\end{tabular}




\section{Solar Resource}

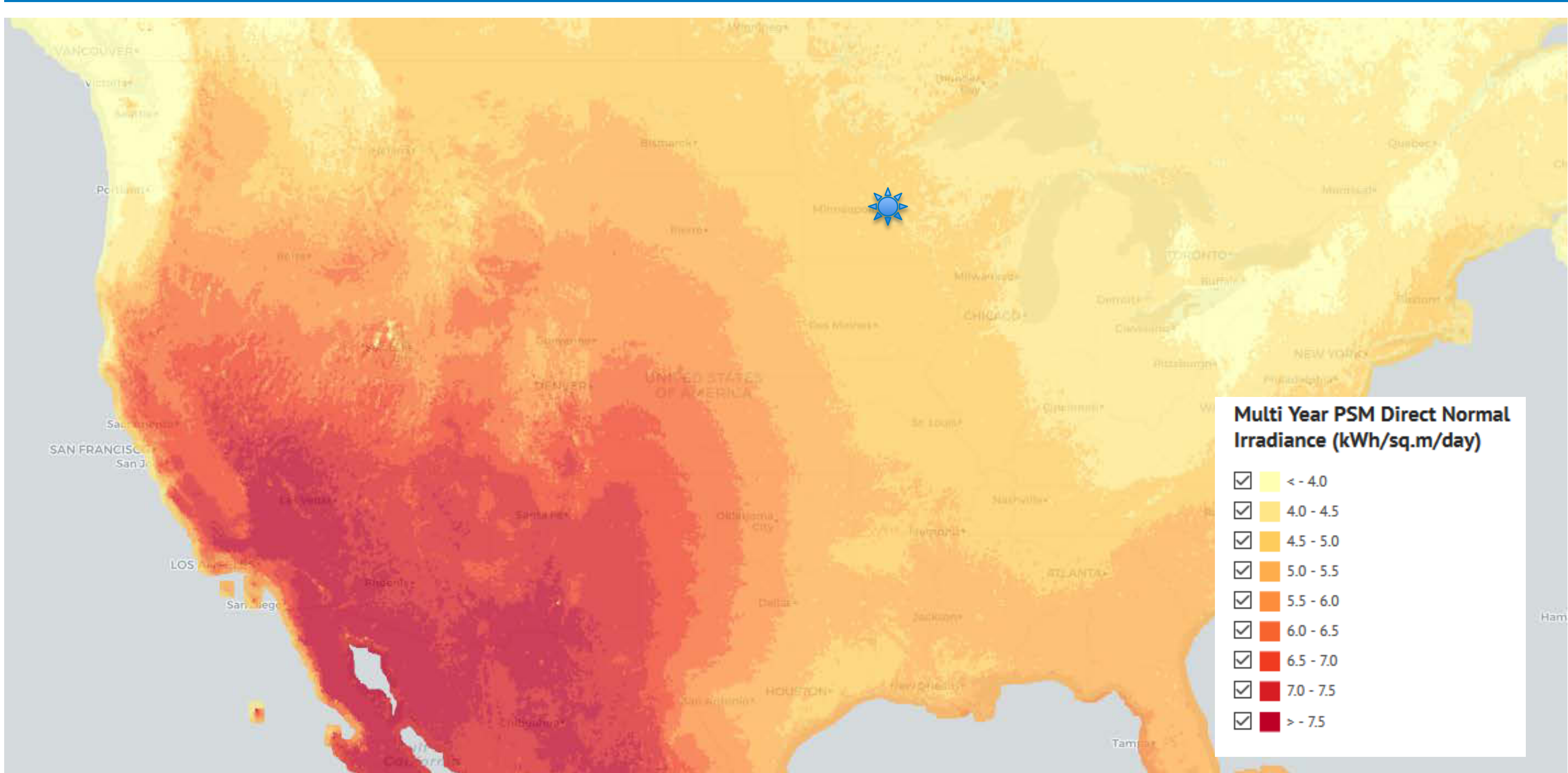

Multi Year PSM Direct Normal Irradiance (kWh/sq.m/day)

$\square<-4$.

$\square \quad 4.0-4.5$

$\square \quad 4.5-5.0$

$\square \quad 5.0-5.5$

$\square \square .5-6.0$

$\square \square 6.0-6.5$

田 $6.5-7.0$

曰 $7.0-7.5$

$\square$ > 7.5 


\section{Solar Resource Data for Minneapolis, MN}

\begin{tabular}{|lrr|}
\hline Month & $\begin{array}{r}\text { Solar Radiation } \\
\text { (kWh/m²/day) }\end{array}$ & $\begin{array}{r}\text { AC Energy } \\
\text { (kWh) }\end{array}$ \\
\hline January & 2.89 & 78 \\
\hline February & 3.76 & 92 \\
\hline March & 4.99 & 130 \\
\hline April & 5.57 & 131 \\
\hline May & 5.93 & 141 \\
\hline June & 6.22 & 141 \\
\hline July & 6.73 & 151 \\
\hline August & 6.08 & 140 \\
\hline September & 5.09 & 116 \\
\hline October & 3.60 & 90 \\
\hline November & 2.85 & 72 \\
\hline December & 2.32 & 62 \\
\hline \hline Annual & 4.67 & $\mathbf{1 , 3 4 4}$ \\
\hline
\end{tabular}

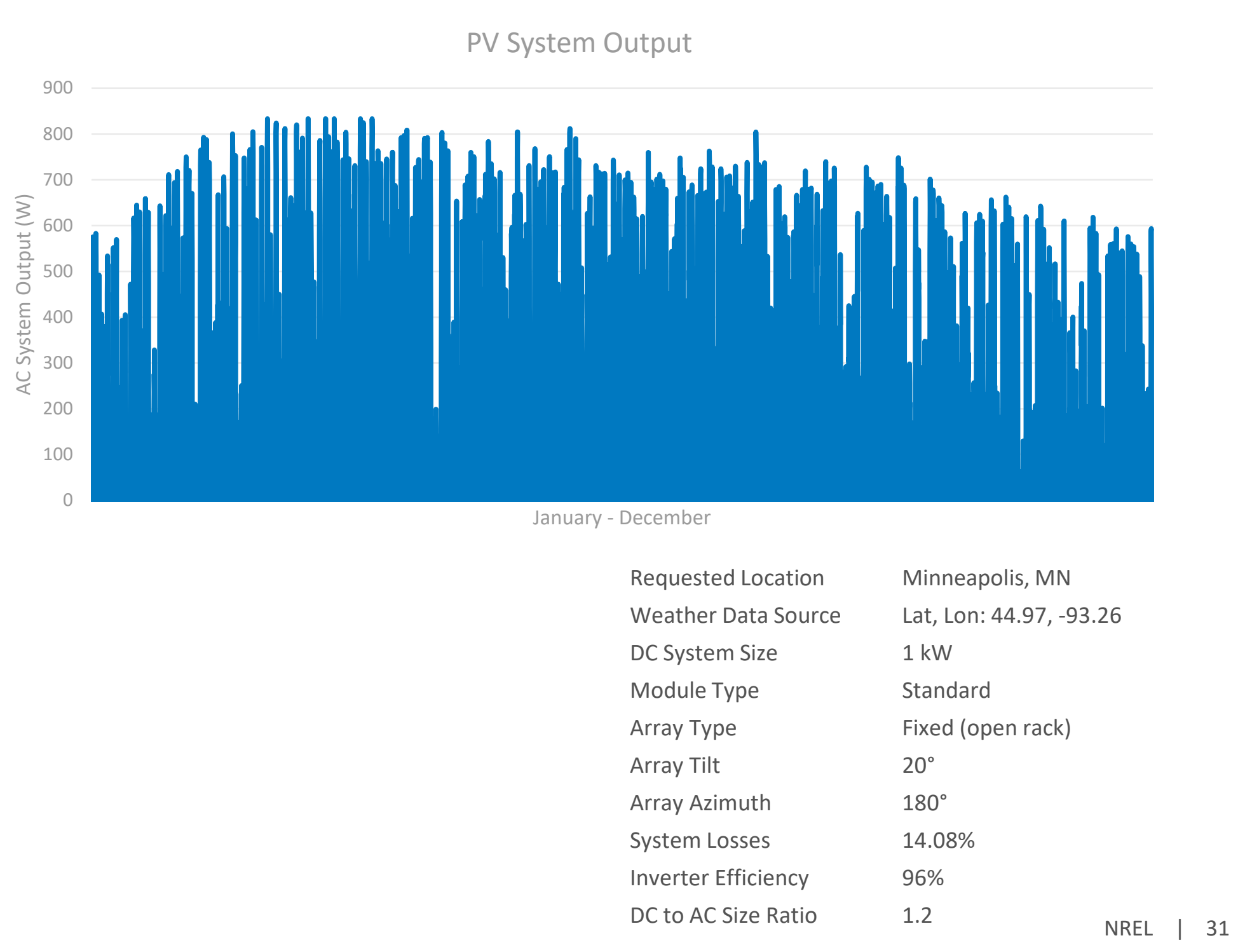




\section{Electric Rate Tariffs for Xcel in Minneapolis}

Rate Name

General Service Time-of-Day Unmetered (A19) Transmission Voltage

General Service Time-of-Day Unmetered (A19) Transmission Tranformed Voltage

General Service Time-of-Day Unmetered (A19) Primary Voltage

General Service Time-of-Day Unmetered (A19) Secondary Voltage

General Service Time-of-Day kWh Metered (A17) Transmission Voltage

General Service Time-of-Day kWh Metered (A17) Transmission Transformed Voltage

General Service Time-of-Day kWh Metered (A17) Primary Voltage

General Service Time-of-Day kWh Metered (A17) Secondary Voltage

General Service Time-of-Day Metered (A15) Transmission Voltage

General Service Time-of-Day Metered (A15) Transmission Transformed Voltage

General Service Time-of-Day Metered (A15) Primary Voltage

General Service Time-of-Day Metered (A15) Secondary Voltage

General Service (A14) Transmission Voltage

General Service (A14) Transmission Transformed Voltage

General Service (A14) Primary Voltage

General Service (A14) Secondary Voltage

Small General Time-of-Day Unmetered Service (A18)

Small General Time-of-Day kWh Metered Service (A16)

Small General Time-of-Day Metered Service (A12)

Small General Service Direct Current (A13)

Small General Service Water Heating (A11)

Small General Service Metered (A10)

Small General Service Unmetered (A09)

Utility Name: Northern States Power Co - Minnesota (Xcel); approved and bundled rates

Other rates to consider include RPU Medium General Service and Connexus General Commercial
Sector

Commercial

Commercial

Commercial

Commercial

Commercial

Commercial

Commercial

Commercial

Commercial

Commercial

Commercial

Commercial

Commercial

Commercial

Commercial

Commercial

Commercial

Commercial

Commercial

Commercial

Commercial

Commercial

Commercial
Service Type Latest Update

Bundled

Bundled

Bundled

Bundled

Bundled

Bundled

Bundled

Bundled

Bundled

Bundled

Bundled

Bundled

Bundled

Bundled

Bundled

Bundled

Bundled

Bundled

Bundled

Bundled

Bundled

Bundled

Bundled
2018-02-20 13:02:44

2018-02-20 13:00:51

2018-02-20 12:58:48

2018-02-20 12:56:23

2018-02-20 12:54:21

2018-02-20 12:52:25

2018-02-20 12:50:37

2018-02-20 12:48:49

2018-02-20 12:46:08

2018-02-20 12:43:16

2018-02-20 12:41:01

2018-02-20 12:38:45

2018-02-20 12:35:14

2018-02-20 12:32:30

2018-02-20 12:29:56

2018-02-20 12:27:08

2018-02-20 12:23:34

2018-02-20 12:21:57

2018-02-20 12:19:20

2018-02-20 12:13:05

2018-02-20 12:10:07

2018-02-20 12:08:31

2018-02-20 12:06:58 


\section{Building Load Profile DOE Commercial Reference Buildings}

\begin{tabular}{|ll|}
\hline Climate Zone & Representative City \\
\hline A & $\begin{array}{l}\text { Miami, FloridaClimate } \\
\text { Zone Table }\end{array}$ \\
\hline 2A & Houston, Texas \\
\hline 2B & Phoenix, Arizona \\
\hline 3A & Atlanta, Georgia \\
\hline 3B-Coast & Los Angeles, California \\
\hline 3B & Las Vegas, Nevada \\
\hline 3C & San Francisco, California \\
\hline 4A & Baltimore, Maryland \\
\hline 4B & Albuquerque, New Mexico \\
\hline 4C & Seattle, Washington \\
\hline 5A & Chicago, Illinois \\
\hline 5B & Boulder, Colorado \\
\hline 6A & VIInneapolis, IVInnesota \\
\hline 6B & Helena, Montana \\
\hline 7 & Duluth, Minnesota \\
\hline 8 & Fairbanks, Alaska \\
\hline
\end{tabular}

\begin{tabular}{|lrrr|}
\hline Building Type Name & Floor Area (ft ${ }^{2}$ ) & Number of Floors & Electricity Use (kWh/yr) \\
\hline Hospital & 241,351 & 5 & $8,425,063$ \\
\hline Large Office & 498,588 & 12 & $6,306,693$ \\
\hline Secondary School & 210,887 & 2 & $2,498,647$ \\
\hline Large Hotel & 122,120 & 6 & $2,378,872$ \\
\hline Supermarket & 45,000 & 1 & $2,034,650$ \\
\hline Outpatient Health Care & 40,946 & 3 & $1,582,701$ \\
\hline Primary School & 73,960 & 1 & $1,022,667$ \\
\hline Medium Office & 53,628 & 3 & $1,005,875$ \\
\hline Small Hotel & 43,200 & 4 & 774,571 \\
\hline Stand-alone Retail & 24,962 & 1 & 539,203 \\
\hline Strip Mall & 22,500 & 1 & 511,567 \\
\hline Full Service Restaurant & 5,500 & 1 & 330,920 \\
\hline Midrise Apartment & 33,740 & 4 & 267,383 \\
\hline Warehouse & 52,045 & 1 & 249,332 \\
\hline Quick Service Restaurant & 2,500 & 1 & 188,368 \\
\hline Small Office & 5,500 & 1 & 85,921 \\
\hline
\end{tabular}

Electricity use for existing Euirbank, Alaska ${ }^{8}$ constructed in or after 1980 ("post-1980") in climate zone 6A 


\section{Annual Electricity Use}

\section{Commercial Reference Buildings Electricity Use}

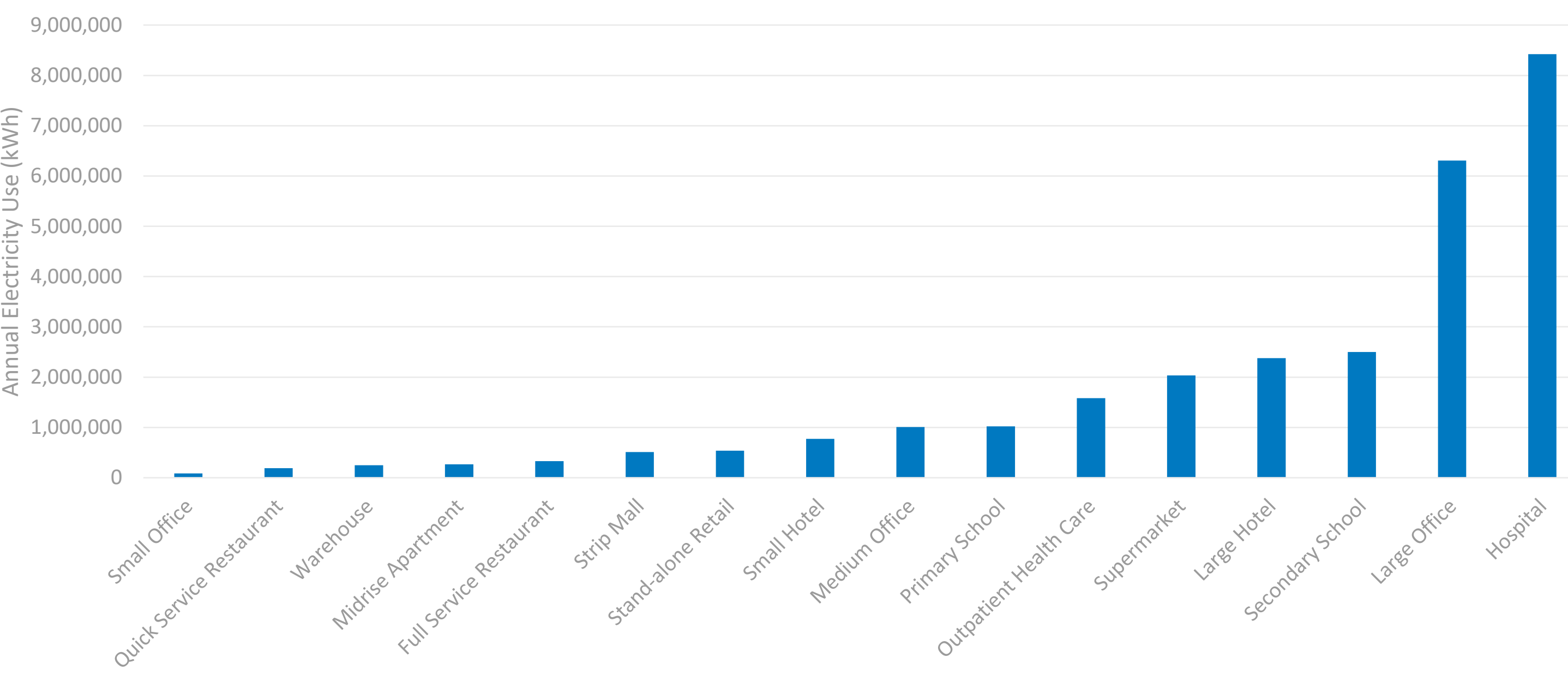




\section{DOE Load Profiles}

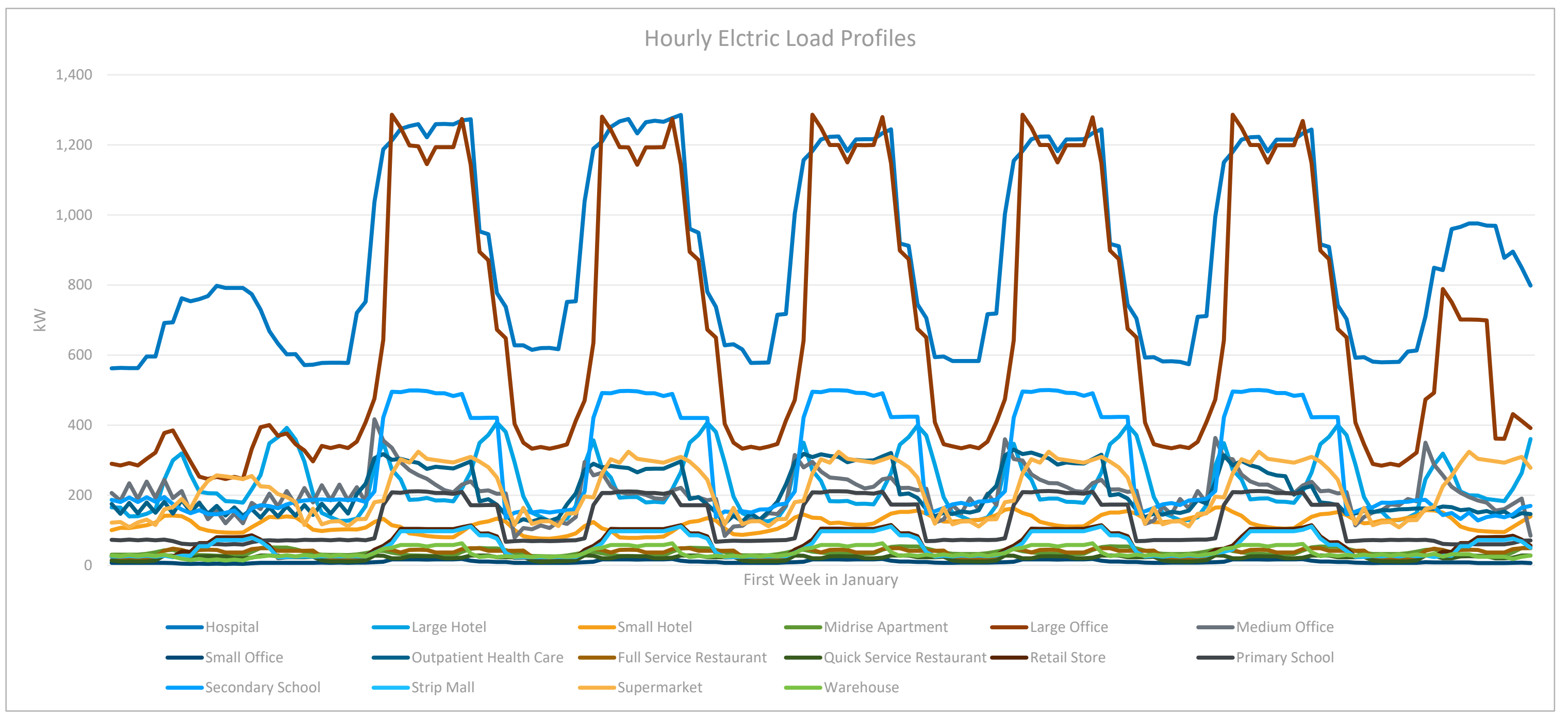




\section{EV Load Profiles}

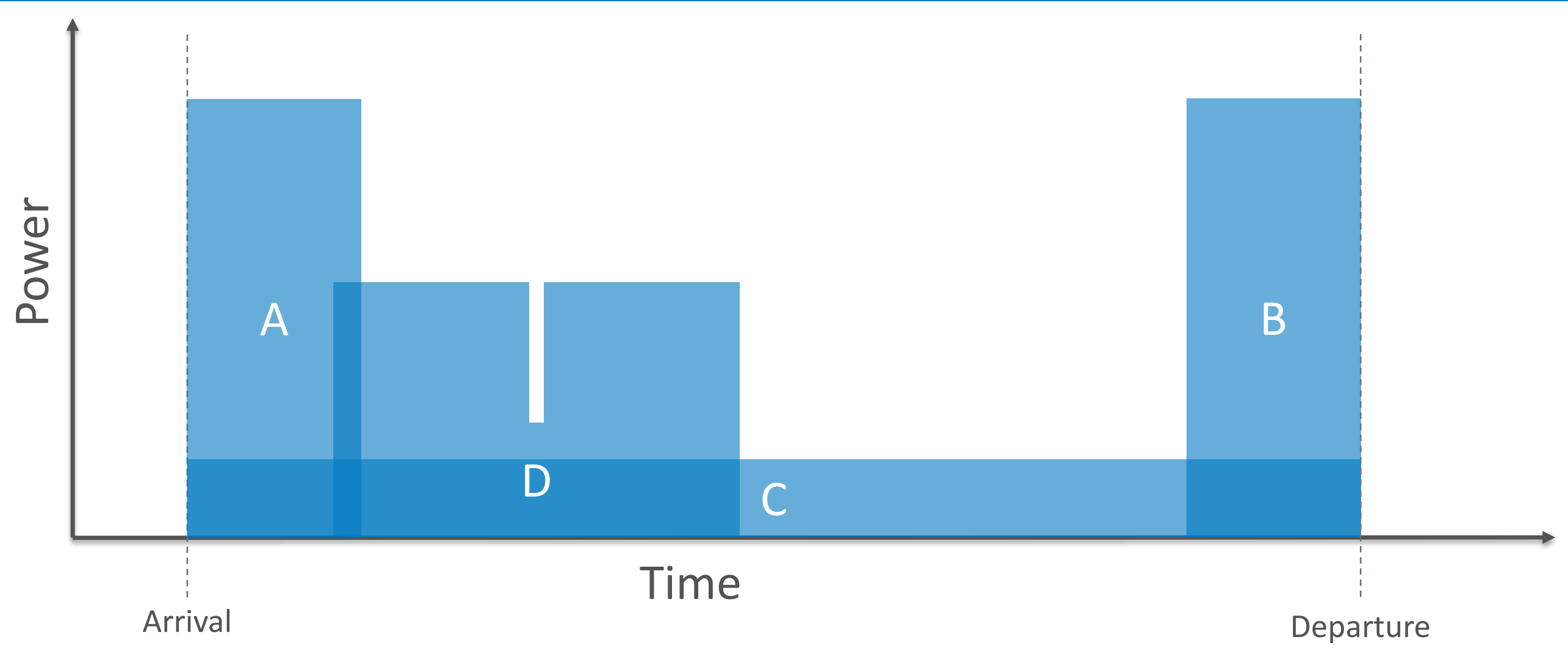

A: Start charging at max power as soon as vehicle arrives

$\mathrm{B}$ : Delays charging as long as possible at max power until departure

C: Charges with minimum power possible between arrival and departure

D: Optimal charging strategy to minimize lifecycle cost of electricity purchases (illustrative example) 


\section{EV Load Input for Flexible Load Profile}

Location of Vehicles

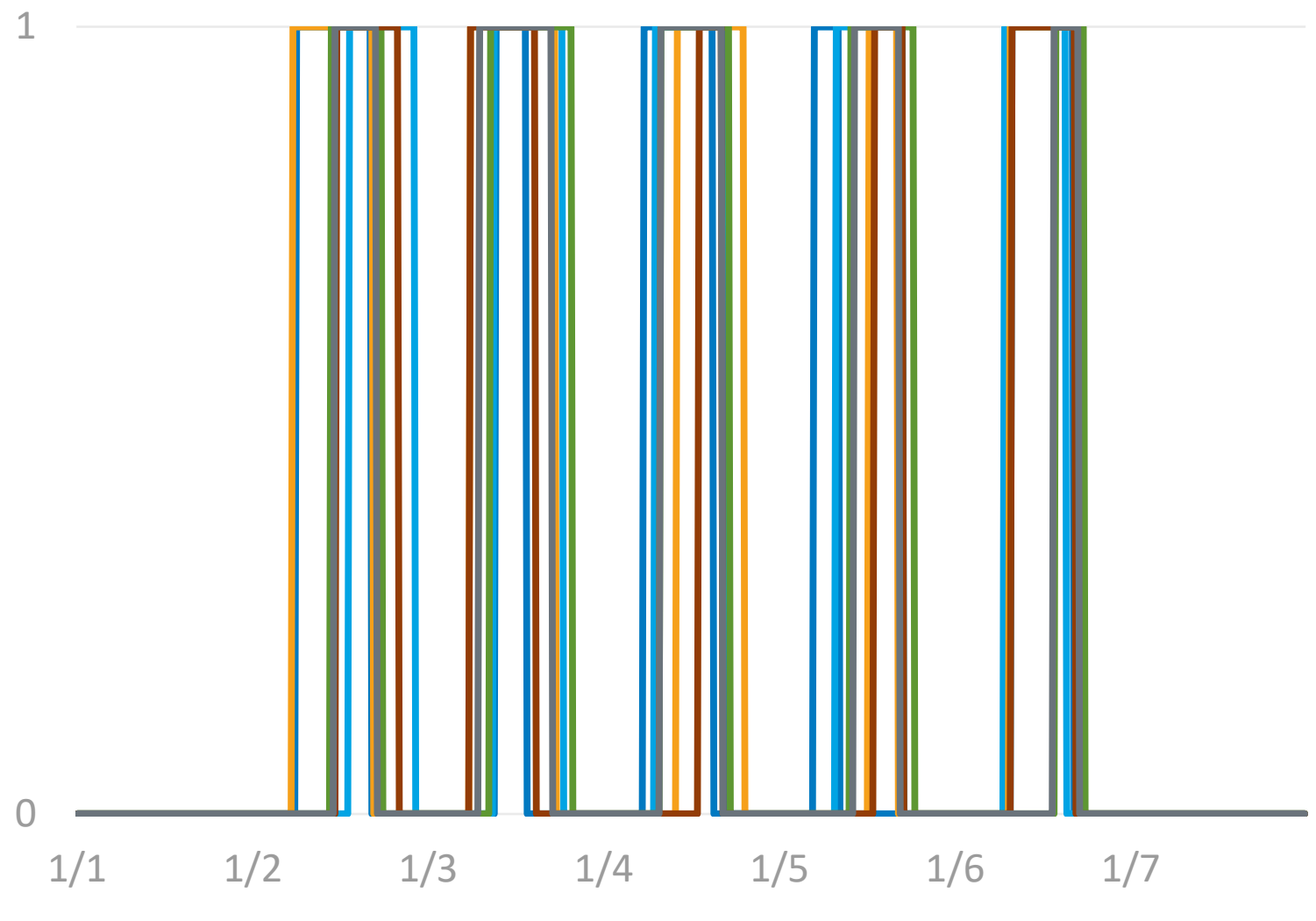

- Charger 1 - Charger 2 - Charger 3

- Charger 4 -Charger 5 -Charger 6

Location of EV

1 - At workplace charger

0 - Not at workplace charger
Energy Requirement by Departure Time (by Charger)
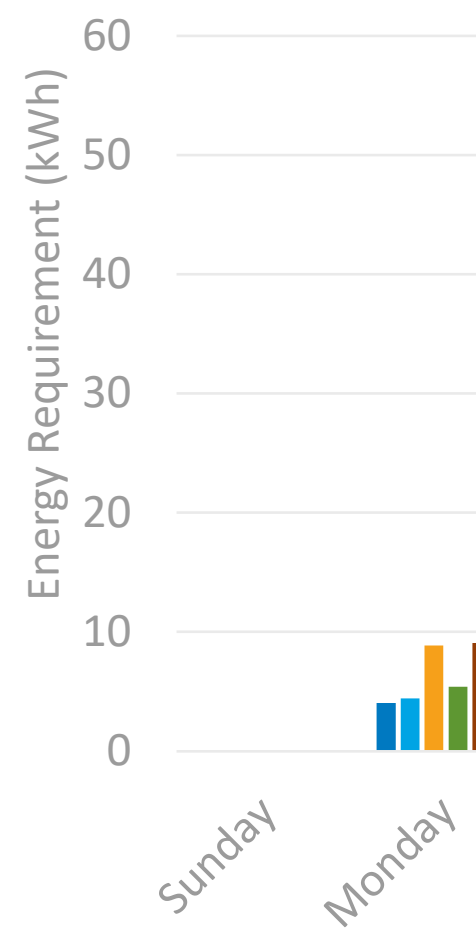


\section{Office and EV Load Profile - Full Year}

Office and EV Load for Full Year

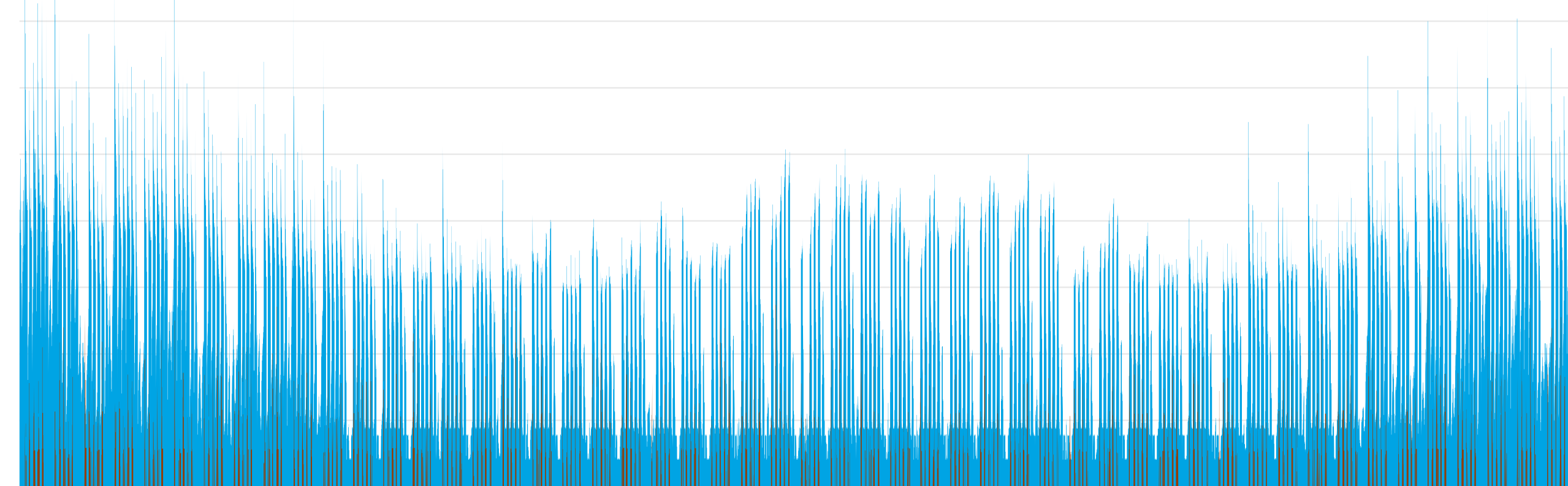

Full Year (January - December)

- Medium Office Load

- Total EV Load 